\title{
Efficient removal of arsenic species by green rust sulfate $\left(\mathrm{GR}_{\mathrm{SO} 4}\right)$
}

\author{
J.P.H. Perez ${ }^{1,2}$, H.M. Freeman ${ }^{1}$, J.A. Schuessler ${ }^{1}$ \& L.G. Benning ${ }^{1,2}$ \\ ${ }^{1}$ Helmholtz Centre Potsdam - GFZ German Research Centre for Geosciences, Potsdam, Germany \\ ${ }^{2}$ Institute of Geological Sciences, Department of Earth Sciences, Free University of Berlin, Berlin, Germany
}

\begin{abstract}
The interfacial reactivity between green rust sulfate $\left(\mathrm{GR}_{\mathrm{SO} 4}\right)$ and arsenic (As) species were investigated using batch adsorption experiments. $\mathrm{GR}_{\mathrm{SO} 4}$ is capable of adsorbing up to 155 and $88 \mathrm{mg} \mathrm{g}^{-1}$ of $\mathrm{As}(\mathrm{III})$ and $\mathrm{As}(\mathrm{V})$, respectively. The value of $\mathrm{pH}$ greatly affects adsorption, with $\mathrm{As}(\mathrm{III})$ removal 2.5 times higher at alkaline $\mathrm{pH}$, while $\mathrm{As}(\mathrm{V})$ removal higher at circum-neutral conditions. Competing groundwater species such as magnesium $\left(\mathrm{Mg}^{2+}\right)$ or phosphate $\left(\mathrm{PO}_{4}^{3-}\right)$ reduce removal efficiency. Our results show that $\mathrm{GR}_{\mathrm{SO}}$ is a stable, efficient and environmentally-relevant mineral substrate for As sequestration in anoxic groundwater systems.
\end{abstract}

\section{INTRODUCTION}

Due to its wide-spread distribution, toxicity and mobility, arsenic (As) contamination of groundwater resources remains a significant problem worldwide. Although conventional remediation techniques (e.g., oxidation, coagulation-flocculation, ion exchange) are widely employed for clean up, they are often too costly and environmentally unsuitable (Nicomel et al., 2016).

In contrast, adsorption-based strategies are promising alternatives for groundwater treatment due to their facile implementation, cost-effectiveness and high removal efficiency (Leus et al., 2017). However, interfacial reactions between (redox-active) mineral surfaces and contaminants such as As need to be quantitatively assessed in order to maximize their potential for subsurface remediation. Moreover, there is an imminent challenge regarding the development and testing of adequate (redox-active) mineral phases that have high metal-specific uptake capacities, strong binding affinities and excellent stabilities.

Herein, we report an in-depth investigation on the interfacial interactions between freshly precipitated green rust sulfate $\left(\mathrm{GR}_{\mathrm{SO} 4}\right)$ and aqueous As species. We tested the influence of $\mathrm{pH}$, adsorbent loading, ionic strength and presence of potentially interfering ions and evaluated the performance of $\mathrm{GR}_{\mathrm{SO} 4}$ for the removal of $\mathrm{As}(\mathrm{III})$ and $\mathrm{As}(\mathrm{V})$.

\section{EXPERIMENTAL SECTION}

\subsection{Synthesis and characterization of $G R_{S O 4}$}

$\mathrm{GR}_{\mathrm{SO} 4}$ was synthesized in an anaerobic chamber $\left(95 \% \mathrm{~N}_{2}, 5 \% \mathrm{H}_{2}\right)$ by co-precipitating stoichiometric amounts of $\left(\mathrm{NH}_{4}\right)_{2} \mathrm{Fe}\left(\mathrm{SO}_{4}\right)_{2} \cdot 6 \mathrm{H}_{2} \mathrm{O}$ and $\mathrm{Fe}_{2}\left(\mathrm{SO}_{4}\right)_{3}$ with $\mathrm{NaOH}$ (Géhin et al., 2002). The obtained
$\mathrm{GR}_{\mathrm{SO} 4}$ was characterized by X-ray powder diffraction (XRPD), inductively coupled plasma optical emission spectroscopy (ICP-OES), transmission electron microscopy (TEM) and electron energy loss spectroscopy (EELS).

\subsection{Adsorption experiments}

Batch adsorption experiments were done at room temperature, with $\mathrm{GR}_{\mathrm{SO} 4}$ suspensions reacted at $\mathrm{pH} 7$ to 9 with $10 \mathrm{mg} \mathrm{L}^{-1}$ aqueous $\mathrm{As}(\mathrm{III})$ and $\mathrm{As}(\mathrm{V})$ through shaking at $250 \mathrm{rpm}$ for $24 \mathrm{~h}$. The resulting samples were filtered, supernatants acidified and the separated solid and aqueous phased stored at $4^{\circ} \mathrm{C}$ until analysis.

\section{RESULTS AND DISCUSSION}

\subsection{Influence of adsorption parameters}

$\mathrm{As}(\mathrm{V})$ was efficiently removed ( $>99 \%$ ) at all tested $\mathrm{pH}$ values. However, the As(III) removal increased significantly from 50 at $\mathrm{pH} 7$ to $95 \%$ at $\mathrm{pH} 9$, likely due to the possible formation of multi-nuclear As(III) complexes on the $\mathrm{GR}_{\mathrm{SO} 4}$ surface (Ona-Nguema et al., 2009; Wang et al., 2010).

Removal efficiency decreased as ionic strength increased from 0.005 to $0.5 \mathrm{M}$, with $\mathrm{As}(\mathrm{V})$ removal dropping by $\sim 10 \%$ at high ionic strength (from $>99$ to $90 \%$ ). On the other hand, inhibition of $\mathrm{As}(\mathrm{III})$ removal was more apparent, with removal efficiency decreasing from 59 to $38 \%$. This reduction in As removal may be caused by the presence of potentially interfering species in the bulk solution. Hence, competitive adsorption experiments were conducted using binary solutions of As with calcium $\left(\mathrm{Ca}^{2+}\right)$, magnesium $\left(\mathrm{Mg}^{2+}\right)$ and phosphorous $\left(\mathrm{PO}_{4}^{3-}\right)$. 
The competitive adsorption results suggest that $\mathrm{Mg}^{2+}$ and $\mathrm{PO}_{4}^{3-}$ can inhibit the adsorption of As on the $\mathrm{GR}_{\mathrm{SO} 4}$ surface, while $\mathrm{Ca}^{2+}$ is not affecting As adsorption. In the presence of $\mathrm{Mg}^{2+}, \mathrm{As}(\mathrm{III})$ and As(V) removal decreased by $\sim 7$ and $\sim 22 \%$, respectively. $\mathrm{Mg}^{2+}$ can block the access of As to the surface active sites of $\mathrm{GR}_{\mathrm{SO} 4}$ due to the formation of outersphere hydrated complexes (Lightstone et al., 2001). On the other hand, co-existing $\mathrm{PO}_{4}^{3-}$ species resulted in the reduction of the removal efficiency by $\sim 7$ and $\sim 25 \%$ for $\mathrm{As}(\mathrm{III})$ and $\mathrm{As}(\mathrm{V})$, respectively. This is a consequence of the competition between $\mathrm{PO}_{4}^{3-}$ and As species for surface binding sites due to their similar structure (Bocher et al., 2004).

\subsection{Adsorption kinetics and isotherms}

Adsorption kinetic data showed that a pseudo-2nd order kinetic model gives the best fit $\left(R^{2} \geq 0.9990\right)$ and that the uptake rate of $\mathrm{As}(\mathrm{III})$ and $\mathrm{As}(\mathrm{V})$ were 4 and 11 times faster at alkaline conditions compared to circum-neutral $\mathrm{pH}$.

The equilibrium adsorption data were fitted to the Langmuir and Freundlich isotherms. Based on the model fits, As adsorption onto $\mathrm{GR}_{\mathrm{SO} 4}$ can be best described by a Langmuir model, a result that supports previous X-ray absorption spectroscopic studies (Jönsson and Sherman, 2008; Wang et al., 2010) that suggested that As species form monodentate mononuclear and bidentate binuclear inner-sphere complexes at GR particle edges.

Using the Langmuir isotherm model, the maximum adsorption capacity $\left(q_{\max }\right)$ for As onto $\mathrm{GR}_{\mathrm{SO} 4}$ at $\mathrm{pH}$ 7 and 8-9 was evaluated. Our results show that at alkaline $\mathrm{pH}, \mathrm{GR}_{\mathrm{SO} 4}$ can adsorb up to $155 \mathrm{mg} \mathrm{As}(\mathrm{III})$ perg of solid, a value 2.5 times higher than at neutral $\mathrm{pH}$. On the contrary, a higher adsorption capacity was observed for $\mathrm{As}(\mathrm{V})$ at neutral $\mathrm{pH}\left(88 \mathrm{mg} \mathrm{g}^{-1}\right)$ compared to alkaline $\mathrm{pH}\left(67 \mathrm{mg} \mathrm{g}^{-1}\right)$.

\subsection{Environmental implications on the fate and mobility of As}

We show that $\mathrm{GR}_{\mathrm{SO} 4}$ has an excellent ability to adsorb As species and has the highest sorption capacity of any iron (oxyhydr)oxides found in surface and nearsurface environments, including ferrihydrite, goethite, hematite, maghemite and magnetite. In terms of surface coverages, $\mathrm{GR}_{\mathrm{SO} 4}$ outperforms all of these phases (Fig. 1), and more importantly, it is also one of the very few redox active mineral phases that exhibits unusually high As(III) coverage.

Finally, we show that $\mathrm{GR}_{\mathrm{SO} 4}$ remains stable post-As adsorption at typical contaminated groundwater conditions $\left(\sim 10 \mathrm{mg} \mathrm{L}^{-1}\right)$. Long term monitoring (three months) of $\mathrm{GR}_{\mathrm{SO} 4}$ samples showed no structural and morphological changes, as confirmed by XRD analysis and TEM imaging. This was supported by analyses of aqueous As in the reacting supernatant, which showed no significant re-release of adsorbed As into the aqueous phase.

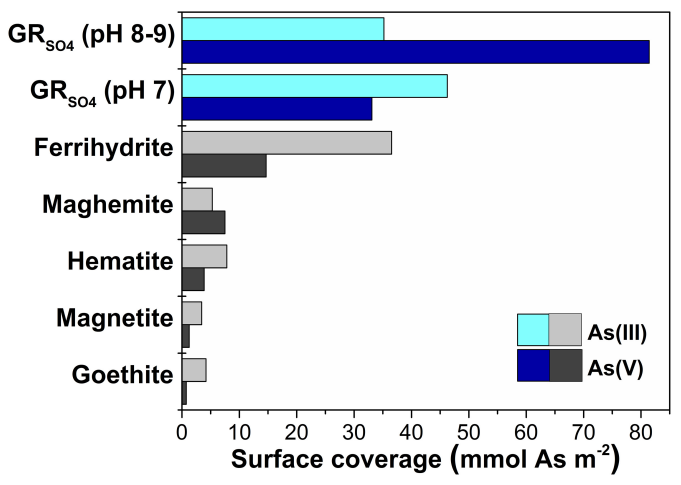

Figure 1. Comparison of As surface coverages of $\mathrm{GR}_{\mathrm{SO} 4}$ (this study) with other iron (oxyhydr)oxides.

\section{CONCLUSIONS}

We quantified the interfacial reactivity between $\mathrm{GR}_{\mathrm{SO}} 4$ and As species. Using batch adsorption experiments, we examined the influence of various critical environmental parameters on As removal. We successfully demonstrated that $\mathrm{GR}_{\mathrm{SO} 4}$ is a highly effective and stable mineral adsorbent compared to other iron (oxyhydr)oxide phases at the concentration of As-contaminated groundwater $\left(\sim 10 \mathrm{mg} \mathrm{L}^{-1}\right)$. $\mathrm{GR}_{\mathrm{SO} 4}$ demonstrated an exceptional As sorption reactivity which makes it a potentially novel and environmentally-relevant mineral substrate for the sequestration of As in reduced groundwater systems. Overall, our results provide important insights as to how uptake and release of As in contaminated groundwaters can be influenced by the presence of redox-active GR phases.

\section{ACKNOWLEDGEMENTS}

This project has received funding from the European Union's Horizon 2020 research and innovation programme under the Marie Sklodowska-Curie grant agreement No. 675219 and the German Helmholtz Recruiting Initiative funding to LGB and HMF.

\section{REFERENCES}

Bocher, F., Géhin, A., Ruby, C., Ghanbaja, J., Abdelmoula, M. \& Génin, J.-M.R. 2004. Coprecipitation of Fe(IIIII) hydroxycarbonate green rust stabilised by phosphate adsorption. Solid State Sci. 6(1): 117-124.

Géhin, A., Ruby, C., Abdelmoula, M., Benali, O., Ghanbaja, J., Refait, P. \& Génin, J.-M.R. 2002. Synthesis of Fe(IIIII) hydroxysulphate green rust by coprecipitation. Solid State Sci. 4(1): 61-66.

Jönsson, J. \& Sherman, D.M. 2008. Sorption of As(III) and $\mathrm{As}(\mathrm{V})$ to siderite, green rust (fougerite) and magnetite: implications for arsenic release in anoxic groundwaters. Chem. Geol. 255(1-2): 173-181. 
Leus, K., Perez, J.P.H., Folens, K., Meledina, M., Van Tendeloo, G., Du Laing, G. \& Van Der Voort, P. 2017. UiO-66-( $\mathrm{SH})_{2}$ as stable, selective and regenerable adsorbent for the removal of mercury from water under environmentally-relevant conditions. Faraday Discuss. 201: 145-161.

Lightstone, F.C., Schwegler, E., Hood, R.Q., Gygi, F. \& Galli, G. (2001). A first principles molecular dynamics simulation of the hydrated magnesium ion. Chem. Phys. Lett. 343(5-6): 549-555.

Nicomel, N.R., Leus, K., Folens, K., Van Der Voort, P. \& Du Laing, G. 2016. Technologies for arsenic removal from water: current status and future perspectives. Int. J. Environ. Res. Publ. Health 13(1): 62.
Ona-Nguema, G., Morin, G., Wang, Y., Menguy, N., Juillot, F., Olivi, L., Aquilanti, G., Abdelmoula, M., Ruby, C., Bargar, J.R., Guyot, F., Calas, G. \& Brown, Jr, G.E. 2009. Arsenite sequestration at the surface of nano- $\mathrm{Fe}(\mathrm{OH})_{2}$, ferrouscarbonate hydroxide, and green-rust after bioreduction of arsenic-sorbed lepidocrocite by Shewanella putrefaciens. Geochim. Cosmochim. Acta 73(5): 1359-1381.

Wang, Y., Morin, G., Ona-Nguema, G., Juillot, F., Guyot, F., Calas, G. \& Brown, G.E. 2010. Evidence for different surface speciation of arsenite and arsenate on green rust: an EXAFS and XANES Study. Environ. Sci. Technol. 44(1): 109-115. 